\title{
Misunderstanding as a resource in interaction
}

\author{
Jessica S. Robles \\ Loughborough University
}

\begin{abstract}
The phenomenon of misunderstanding is a recurrent feature of everyday life - sometimes a source of frustration, sometimes a site of blame. But misunderstandings can also be seen as getting interactants out of (as well as into) trouble. For example, misunderstandings may be produced to deal with disaffiliative implications of 'not being on the same page,' and as such they may be deployed as a resource for avoiding trouble. This paper examines misunderstanding as a pragmatic accomplishment, focusing on the uses to which it is put in interactions as a practice for dealing with threats to intersubjectivity: the extent to which persons are aligned in terms of a current referent, activity, assessment, etc. A multimodal discourse analysis of audio and video recordings of naturally-occurring talk inspects moments in which misunderstandings are purported or displayed (rather than overtly invoked) as well as how such misunderstandings are oriented to as simply-repairable references, versus inferential matters more misaligned and potentially fraught. Rather than being a straightforward reflection of an experience of trouble with understanding, misunderstanding may also be collaboratively produced to manage practical challenges to intersubjectivity.
\end{abstract}

Keywords: discourse analysis, misunderstanding, repair, reference, inference, intersubjectivity

"We're not on the same wavelength." "They're talking at cross-purposes." "You've got the wrong end of the stick." There are a number of idioms in the English language characterizing the phenomenon we might call misunderstanding, in which two or more people do not have a shared sense of something - be it some referent (person, place or thing), an activity (how to do something, what a current situation is), and so forth. Many people in their everyday lives tend to think of misunderstandings as a reflection of different knowledge-states. This is also assumed in much of the psychological and cognitive literature. But this paper takes an interactional and pragmatics-based approach, asking instead, "for what practical purposes might misunderstandings be produced?" 
Drawing on multimodal discourse analysis, this analysis examines transcripts of naturally-occurring audio and video recordings in which participants display or attribute 'having misunderstood' as an account for a sequential hiccup in the ongoing interaction. Typically, participants use a number of resources to work up the misunderstanding as simple and unproblematic: as something which ultimately aids in moving a conversation along, and which only for that reason would (as briefly as possible) halt it. Indeed, the preference for progressivity in interaction suggests that even more 'serious' misunderstandings might be treated as simple mismatches of meaning. Conversely, however, apparent 'mere' misunderstandings may be pursued and expanded as a way of doing disagreement. This paper focuses on cases where misunderstandings are produced and managed collaboratively to preclude any potential troubling moral implications of intersubjectivity loss and avoid explicit disagreement. The first section lays out the practices through which participants accomplish misunderstandings, and how these practices show a preference for minimal, referential repairs. The second section analyzes how misunderstandings may exploit inferential ambiguities to manage interactional troubles and avoid disagreement.

This paper begins by reviewing literature on interactional approaches to understanding and intersubjectivity (Section 1), followed by a description of the methods employed and the data analyzed in this paper (Section 2). The analysis (Section 3) reviews a number of cases of purported misunderstanding (in which the misunderstanding is indexed rather than explicitly labeled as such); these cases illustrate pragmatic materials participants draw on for crafting their 'misunderstanding' moments, then present how misunderstanding may be enrolled to avoid or pursue disagreement. The final section (4) reflects on these results and considers the morality of apparent misunderstanding.

\section{Understanding and intersubjectivity in conversation}

'Understanding' is a familiar topic in philosophy and psychology, where exploration has ranged from the hermenutic to the experimental (e.g., Bransford \& Johnson 1972; Kvale 1983; Tamir, Thornton, Contreras \& Mitchell 2016). This research tends to link understanding to knowledge, and knowledge has largely been presumed to be a cognitive matter involving implicit mental models (e.g., Johnson-Laird \& Byrne 2002). Pragmatics approaches that examine language in use (for instance discourse analysis and discursive psychology: Cameron 2001) have by and large set knowledge-as-an-internal-mental-state aside in favor of empirical approaches that look instead at interactional evidence for, or displays of, individual and shared knowledge, shared frames of reference, and epistemics 
(c.f., Bocéréan and Musiol 2009; Drew 2012; Kataoka \& Asahi 2015; Muntigl \& Choi 2010; see Mikesell 2014, for work that combines approaches). Mutual understanding, or intersubjectivity, has often been defined phenomenologically or philosophically as mutuality, empathy, emotional accord, agreement about beliefs, a capacity to see from the other's point of view, and even as opposed to interaction (e.g., Finlay 2009; Gillespie \& Cornish 2010; Hall 2010; Harwood, Stone \& Pines 2012; Johannson 2007). By examining understanding for practical purposes as an interactional achievement rather than a feature of emotion or belief (Koschmann 2011; Lynch 2011; Sadler 2010), this paper focuses on the communicational dimension of the social world, and how participants actively, demonstrably coordinate and construct shared meaning.

In ethnomethodological work (Garfinkel 1967), shared understanding - intersubjectivity - was proposed as the very foundation of human social behavior in daily life. Garfinkel saw intersubjectivity as the shared expectations assumed (and taken for granted) by interactants in their everyday dealings with one another. As Levinson (2006) put it, we attempt to read others' minds and we imagine how others are trying to read ours (see also Duranti 2008); by this method we interpret one another's responses and design our own for them. This assumption is a precondition for interaction and provides for the possibility of communication. This means, practically, that intersubjectivity is presumed to have been accomplished unless signs indicate otherwise (Heritage 1987) and that there is a preference for intersubjectivity in conversation (Heritage 2007; Schegloff 1992).

In conversation analytic (CA) research, this intersubjectivity was proven through sequence (Heritage 1987; Schegloff 1992). In the CA approach, intersubjectivity is grounded in the ways in which participants display understanding of one another's turns by producing intelligible responses. Understanding in interaction is therefore about adjacency and 'nextness' (Mondada 2011): progressively accomplishing actions in discourse. In this way, intersubjectivity is largely implicit, visible in the extent to which the appropriate next turn is produced and accepted. Sacks (1992) described different positions where it is relevant to show more explicit understanding across a sequence. That is, at key sequential placements, there may be a sort of check for understanding from a speaker, or a proffer of understanding from the recipient. These can be as subtle as a minute pause or the use of continuers such as "m hm" and "uh huh." Certain final particles have also been shown to do work in maintaining intersubjectivity in the assumed understanding interlocutors' display of prior utterances (Haselow 2012). Other research distinguishes types of acts that achieve intersubjectivity, such as joint attention versus requesting (Mundy, Kasari \& Sigman 1992), or the coordination of action versus displays of feeling and being (Du Bois 2011). 
But what are such understandings 'about?' Hepburn, Wilkinson and Shaw (2012) show how participants orient to different referents toward which they are managing convergent or divergent understanding. So what is being understood does matter. But that 'what' may refer to very simple or very complicated things, and the understanding required may vary. It is a commonplace that people assume, claim to experience, and comment on different 'depths' of shared meanings, as evidenced in metadiscourse on ideas such as "dialogue," "really communicating," and "deep understanding” (or deep/meta learning) in ordinary and academic talk and texts (e.g., Craig 2008; Katriel \& Philipsen 1981; Osman \& Herring 2007; Rochat, Passos-Ferreira, \& Salem 2009). This intuition we have when adopting the 'natural attitude' that some misunderstandings are small and others big is also reflected in the examples at the start of this article, all of which seem to characterize deeper misunderstandings. In other words, they suggest a misunderstanding is not a misrecognition of a single referent, but a misunderstanding of a situation, the gist of an argument, someone's purpose, etc.: something that is implicit or that has been under management across sequences.

Participants may also treat the content of their understandings as relevantly differentiable in their interactions. Sidnell (2014) describes a number of dimensions of intersubjectivity, from the 'basic' forms of attention and phatic communion, through joint attention and shared stance, to reciprocity, collective intention, and mutual understanding. Each of these dimensions may be considered more or less complex, difficult, serious, and so forth - equally so, those moments where such dimensions are not realized in interaction. In describing the organization of intersubjectivity in turn structure, Sidnell notes that utterances are designed to display understanding of the prior turn and its action, both of which are empirically distinguishable. This is true also of misunderstandings, of which Sidnell lists some common types including problems arising from the use of unfamiliar words, problems of reference, problems of action recognition, and problems with assumptions or common ground. The primary mechanism for correcting these and other sorts of misunderstanding - as well as the phenomenon through which misunderstandings are made visible - is repair.

Schegloff (1992) implemented an empirical analysis of the phenomenon of intersubjectivity based in the CA approach to repair of understanding, or "trouble in the socially shared grasp of the talk and the other conduct in interaction" (p. 1301). Analyses of repairs note that they are overwhelmingly initiated and completed by the speaker of the trouble-source turn (the turn in which the error occurred), within that turn. However, repair can also be initiated (though is rarely completed) by the other participant, and either can do so in between or in subsequent turns. Repair is almost always accomplished in the first or next turn; repair positions that occur after the hearer has indicated trouble are rarer, and generally there must be 
a re-realization of relevance of the trouble-source to provide another opportunity for repair (Schegloff, Jefferson \& Sacks 1977).

In the absence of explicit labeling of interactions as 'misunderstanding, then, repair instances provide empirical insight into the event of a misunderstanding and how it unfolds. Schegloff (1992) defines repair on understanding as a sign of possible loss of intersubjectivity in the derailment of an ongoing interactional project (c.f. Kim 2001; Wilkinson 1999; Wootton 1994). In terms of locating the source of a repairable misunderstanding, participants may identify the source precisely (for instance with closed repair initiation sequences) or use an 'open class repair' (such as "what?") (Drew 1997), the latter of which is canonically deployed as a mishearing repair (Svennevig 2008). Though it can be used as a sort of challenge, according to Schegloff (1987), understanding repairs typically proceed without direct participant attention to aspects of the trouble source beyond talk-endogenous matters. In other words, if an apparent problem with understanding emerges, participants tend to treat the 'fix' as something that is literal and correctable within the context of the immediate local talk itself - as a matter of semantic mismatch, perhaps, or a misrecognition. This is consistent with Heritage's (2007) observation that there is a preference for recognitional and minimized references for doing understanding.

Repair is a fairly frequent cross-cultural phenomenon in which the preference for specific, minimal repairs prevails (Dingemanse, Roberts, Baranova, Blythe, Drew, Floyd, Gisladottir, Kendrick, Levinson, Manrique \& Rossi 2015). Schegloff (1992) suggests that multiple repairs and unrepaired problems sustained over multiple turns can evolve into disagreement. Dispreferred variations such as third and fourth turn repair, other-initiated repair, and pursuits of misunderstanding are used to challenge, to do disagreements, and to accomplish moral assessments of particular actions or of understandings about the world (e.g., Hayashi, Raymond, \& Sidnell 2013; Goodwin 1983). And research has shown that using repair to pursue indexical referentials in the absence of actual uncertainty can be a way of covertly managing potential disagreement or misalignment while only going on record as seeking repair on a referential (Bolden, Mandelbaum \& Wilkinson 2012, Lerner et al. 2012). Thus, different participant courses of action in managing understandings (and misunderstandings) have a number of possible links to dealing with more conflicted forms of trouble with intersubjectivity (Hayashi, Raymond \& Sidnell 2013).

Schegloff's 1992 paper on intersubjectivity was subtitled "the last structurally-provided defense of intersubjectivity." This title suggests a number of interesting things, including (1) that if third position repair is the "last," then there might be other possibilities which come before; (2) that if it's "structurally-provided," then there might be other non-structural strategies; and (3) that if it's a "defense," then there might be intersubjectivity building (as well as defending) practices. Sacks (1992) describes how participants might claim understanding or 
demonstrate understanding ('doing understanding') (Heritage 2007). This paper looks at a number of sequences in which participants 'do misunderstanding' and how intersubjectivity is at stake.

\section{Analyzing misunderstanding}

In the work of discursive psychology (Edwards \& Potter 1992), purportedly-psychological concepts are reanalyzed as interactional phenomena. This paper's analysis takes this approach as a starting point, examining the phenomenon of 'misunderstanding' from a pragmatics-focused approach to language. Using ethnomethodologically-inflected discourse analysis, the analysis also attends to a detailed transcription of discourse and sequential analysis of turn-by-turn acts based on work in conversation analysis (Hutchby \& Wooffitt 2008; Schegloff 2007), while incorporating multimodal elements involving coordination between simultaneous sequences of verbal and nonverbal acts in a semiotic environment of objects and space (e.g., Eriksson 2009; Fox 1999; Goodwin 2000; Heath 2002; Mondada 2009).

The analysis of misunderstanding herein is also problem-centered, insofar as it is interested in how participants manage practical challenges encountered in interaction. Taking the perspective of grounded practical theory (Craig \& Tracy 1995), this analysis reconstructs 'misunderstanding' as a communicative practice designed to manage ordinary dilemmas and troubles. Taking this perspective highlights how the practical use of misunderstanding reveals participants' situated ideals around intersubjectivity. The work that misunderstanding does is underpinned by the moral accountabiltiy of common ground in everyday discourse, as described in ethnomethodology (Garfinkel 1967).

The data analyzed in this project come from a corpus of more than 50 hours of video-taped naturally-occurring or home movie interaction which was recorded in California, Colorado, and New Hampshire in the United States between the late 1930s and 2012. The videos have been transcribed with Jeffersonian notations (Jefferson 1984; see appendix) and some supplemental notations, including visual elements and screen shots (embodied actions are described in data for which visuals cannot be shown due to consent constraints). These data were collected and transcribed as part of an ongoing project on how morality is displayed and constructed in interaction (Robles 2011). The excerpts discussed were selected from a collection of cases in which misunderstandings were made visible. The primary corpus of 62 cases led to an inquiry into how aligning understandings for action may be accomplished or pursued through embodied acts. The current project focuses on misunderstandings that are produced but not explicitly labeled as such, and does not start with the most basic level of intersubjectivity (phatic 
communion, attunement, involvement and engagement - see Sidnell 2014), instead focusing on higher-order intersubjectivities: shared reference, stance coordination, and mutual understanding. The results presented in the following sections examine how misunderstandings are practically accomplished and what actions those misunderstandings are doing to manage intersubjecitivity.

\section{Misunderstanding as an accomplishment and a resource for managing trouble}

The basic sequence through which misunderstandings are produced begins with repair initiation that suggests something (a referent, an implication, the course of action itself) in a prior turn was misunderstood such that the sequence cannot progress. This is generally followed by the repair, then some display of understanding. The first section lays out the techniques through which participants accomplished misunderstandings through repair, in accordance with a preference for minimal, referential repairs, and shows how these maintain intersubjectivity. The first example deals with an immediate case of misrecognition or lack of familiarity with a particular word or the word's referent; and the second example deals with a delayed identification of misrecognition.

\subsection{Misunderstanding for reference and stance alignment}

In the first excerpt, the participants have been discussing their Halloween costumes, as the holiday had recently passed. Meg brings up an idea she had for 'matching' costumes involving herself and her half-brother. In this case the referent for the half-brother's costume "Shortround" is unknown and therefore unrecognizable to the recipient.

(1) "Shortround"

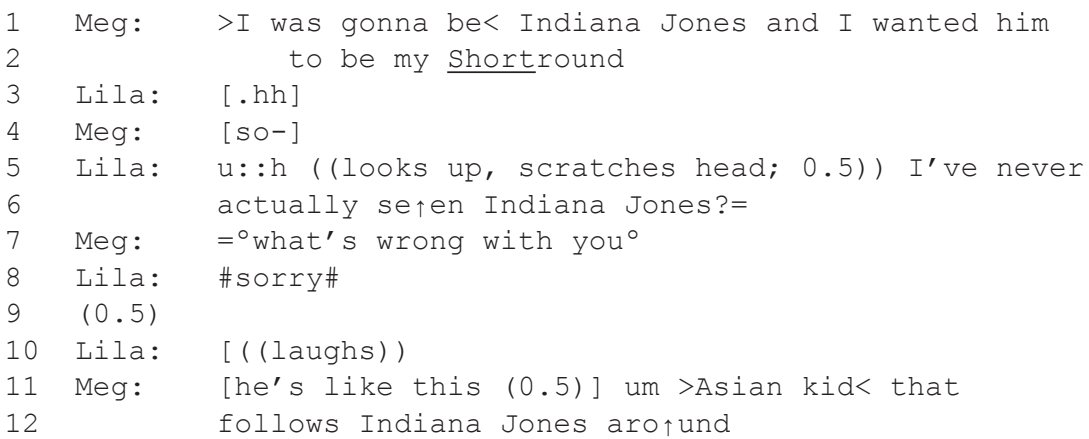


Lila displays no difficulty with having heard Meg's reference to "Shortround," nor a lack of understanding that Shortround is a character: she seems to hear and recognize, in the context of the conversation being about Halloween costumes, that Meg "being" Indiana Jones means she'll dress up as the character for Halloween, and the referenced "him" "being her" Shortround means the "him" will dress up for Halloween as whatever a Shortround is (line 2). The first possible moment at which understanding may be in trouble occurs in line 3 with Lila's in-breath: Meg seems to hear this as a possible initiation of speech (c.f. Scobbie, Schaeffler, \& Mennen 2011) since she stops in mid-initiation of a next turn (line 4). Lila's next turn begins with a drawn-out "uh," which could be doing a word search or signaling confusion; it is a potential sign of trouble and is accompanied by a matching facial expression and gesture (see below) followed by an admission, which implies an account for a confusion without stating what the trouble is.

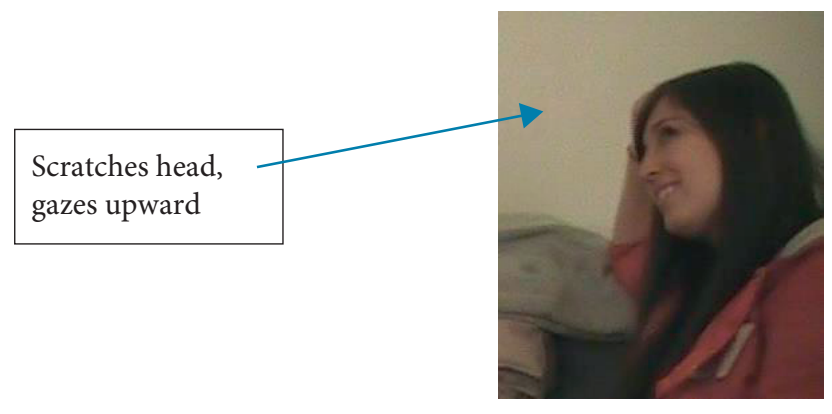

By not specifying the exact source of the trouble, Lila's repair initiation allows Meg the opportunity to identify and correct the trouble, and positions the reasoning as based in Lila's lack of precise knowledge rather than a lack of clarity on Meg's part. Lila's admission that she has not seen Indiana Jones the movie (line 6) indicates some knowledge (for instance, that it's a film, and perhaps the gist of what it's about or who the main character is), but not of particulars, positioning Meg as having greater epistemic access (Heritage 2012) in this regard. That Meg interprets this as a lack of recognition of the specific reference to "Shortround" is evidenced by her treatment of Meg's admission as a repair initiation on the term Shortround, which Meg does by explaining who the character is (lines 11-12).

This repair is initiated and resolved fairly quickly, as is preferred under the presumption of a preference for progressivity - in this case moving forward with the description of Meg's unsuccessful costume idea, which is probably a preface to what her actual costume ended up being, and which may prompt an assessment or similar sharing from Lila as the second pair part (Schegloff 2007). This example shows how Lila displays a lack of recognition on a referent which Meg 
repairs with a description, accomplishing a simple enough understanding of what "Shortround" is to carry on with the conversation, and establishing shared understanding of a particular reference to a movie character. The next example shows a similar sort of misrecognition, but one which is delayed.

(2) "Pocket Shots"

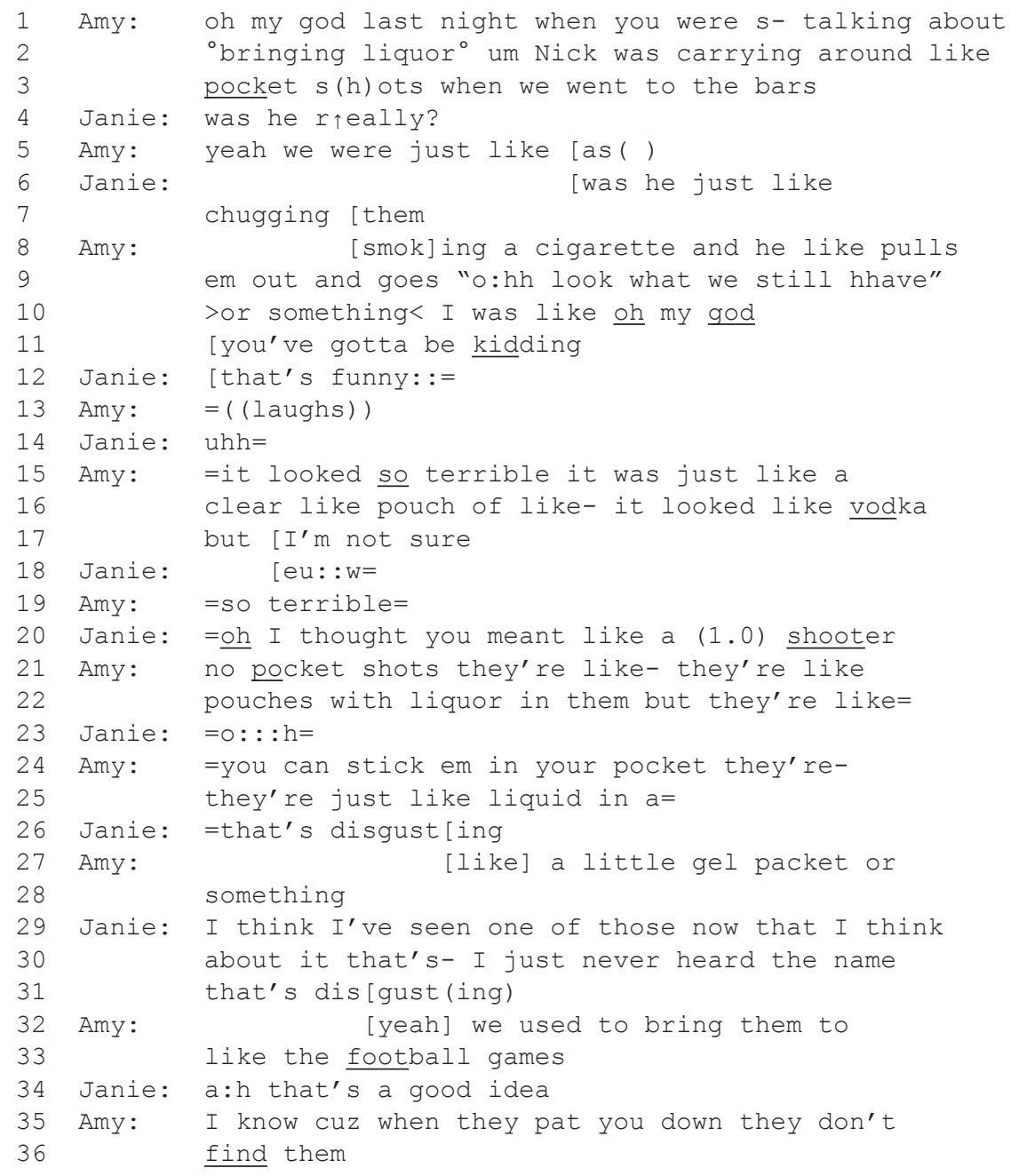

In this excerpt, Amy and Janie discuss the "pocket shots" over the course of several turns before discovering that they may have different referents 'in mind' for this term. The first mention comes with no explanation and is met with no sign of trouble (line 3). The next reference is not by name, but by gesture: as Amy tells her story, she enacts the non-present person's interaction with the aforementioned pocket 
shots (pulling the pocket shots 'out') while referring to 'them' (“em," line 9). As she enacts this performance her hand makes a gesture as if to hold an object with the index finger and thumb and pull it up (and out) of an imaginary place (pocket).

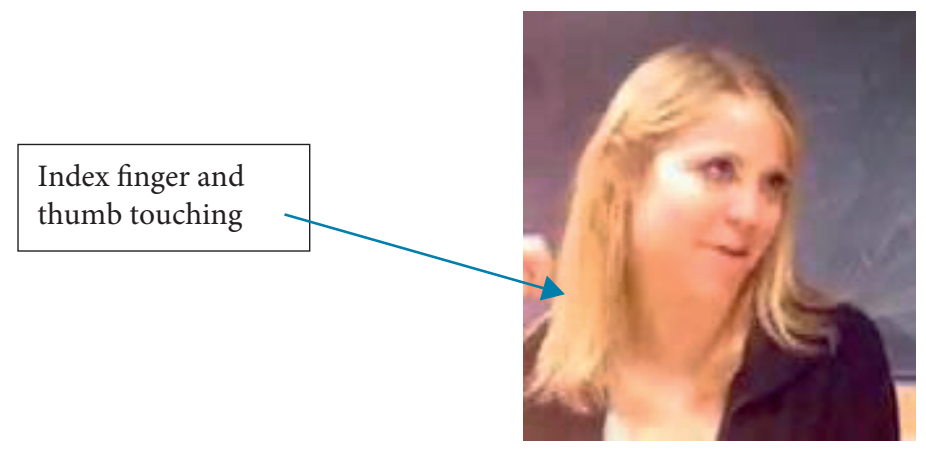

As will become relevant, this is a different way of holding the "object" in question than the way Janie represented the action of "chugging" (a U.S. American colloquialism for taking big, quick gulps) on line 7, which she delivered while making a small circular gesture with one hand and mimicking taking a quick drink (Janie tilts her head back and leans her body back as she makes the chugging gesture, temporarily removing all but her arm and hand from the frame).

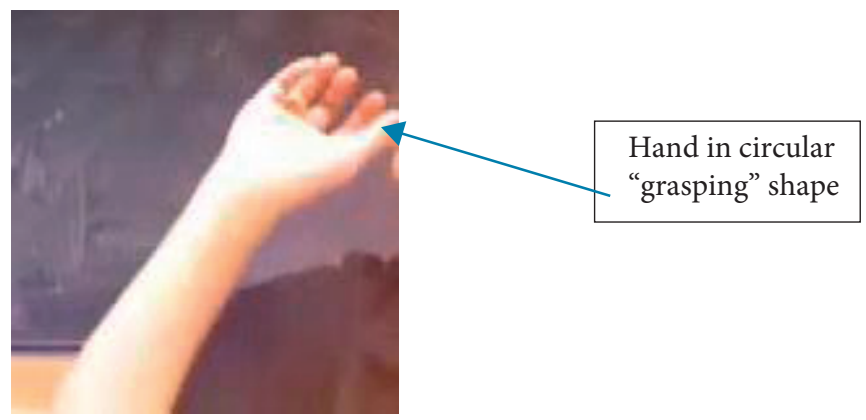

Unless one was paying very careful attention to this small gestural distinction, there is little evidence that Amy and Janie do not mean the same thing by their references to the object "pocket shot." It is at the point of Amy's more detailed description of the pocket shot on line 16 that a possible trouble is identified. Along with her description of the pocket shot as a "clear like pouch," Amy makes a new gesture, holding her index finger and thumb apart, which seems to approximate the size and shape of the pouch, as she says the word "pouch." 


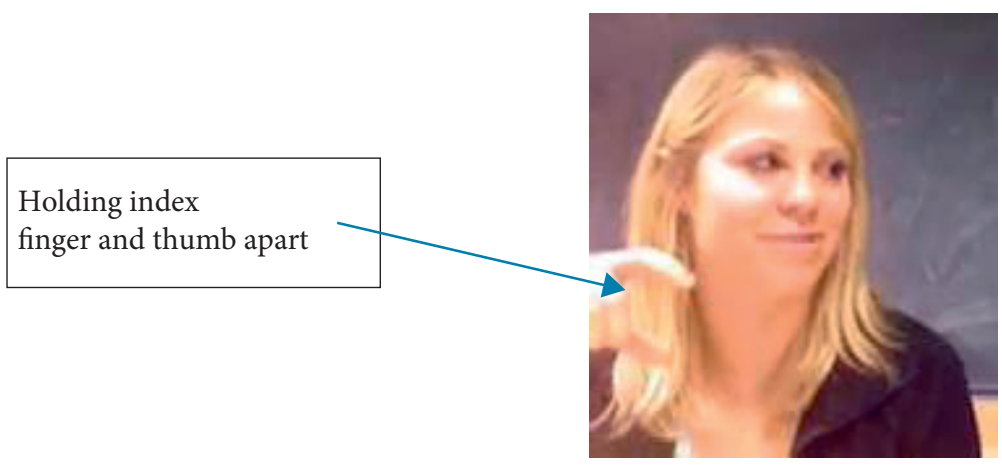

Janie does not bring up any potential discrepancy right away, instead responding to the assessment of the object as looking "so terrible" (line 15) with an aligning response cry (Goffman, 1978) of "euw" (line 18). It is only after Amy repeats "so terrible" (line 19) that the assessment sequence appears to be at a point of possible completion, providing an opportunity to initiate a new action which in this case reopens the repairable outside its more preferred repair space. Janie self-repairs her understanding of the object in third position, offering a formulation of what she hears pocket shots to be by re-labeling the referent a "shooter." She takes a second to select the term "shooter," doing an apparent word-search (c.f. Hayashi 2003; Schegloff, Jefferson \& Sacks 1977). While doing this, she also makes a gesture that she 'shakes' and watches as she performs the word-search, drawing Amy's attention to it. Her gesture is very similar to Amy's prior gesture.

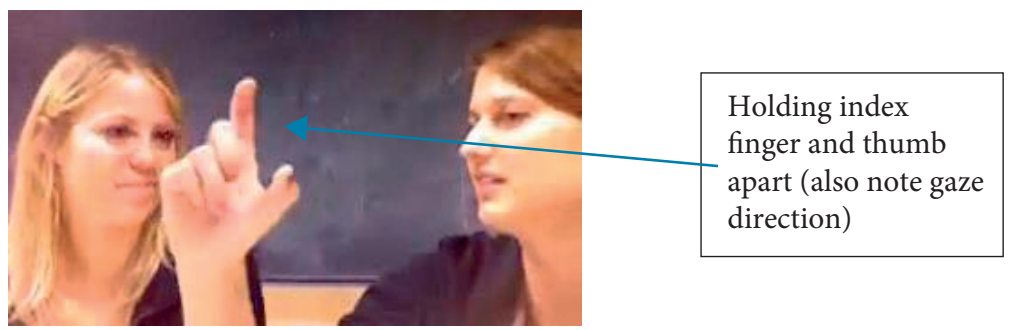

This action does not specify what a shooter is in comparison to a pocket shot. In fact, by making nearly the same gesture, Janie's repair on her own understanding is potentially hearable as a repair on Amy's presentation of what the pocket shot looks like. Amy seems to take this up, as her repair repeats the term "pocket shots" and begins with a repair on the gesture rather than beginning with repair by expanding her previous description ("clear like pouch" line 16). She first brings her hand up with the fingers facing the camera and the thumb behind them, as if holding or imitating a flat object, while she says "pouches" in line 22. 


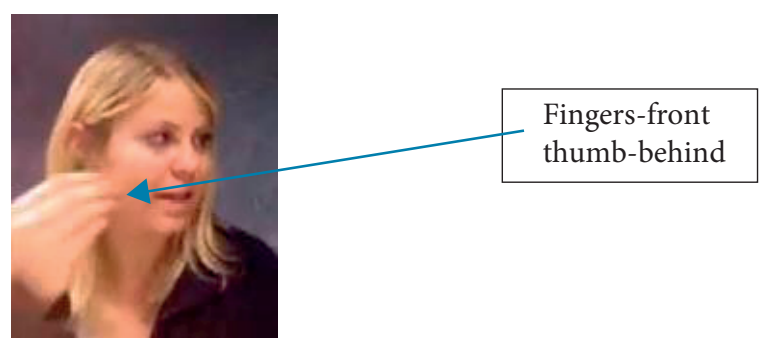

This changes the shape being represented. It is contrastable, for instance, with Janie's "chugging" gesture, which presented the shape as cylindrical; now it appears to be flat. Following this, Amy expands her description of the pocket shot, first repeating largely the substance of her initial description in line 16: "like pouches with liquor in them" (line 22). As she says "liquor," she simultaneously holds her right hand in a slightly clasped position with bent index finger and thumb touching (below) while holding her left hand underneath in the same fingers-front thumb-behind gesture with which she initiated the repair (above). She then tips her hand forward as she says "in them," indicating that her raised hand is demonstrating the "liquor," her lower hand the "pouch," and her tipping gesture a representation of putting liquor into a pouch.

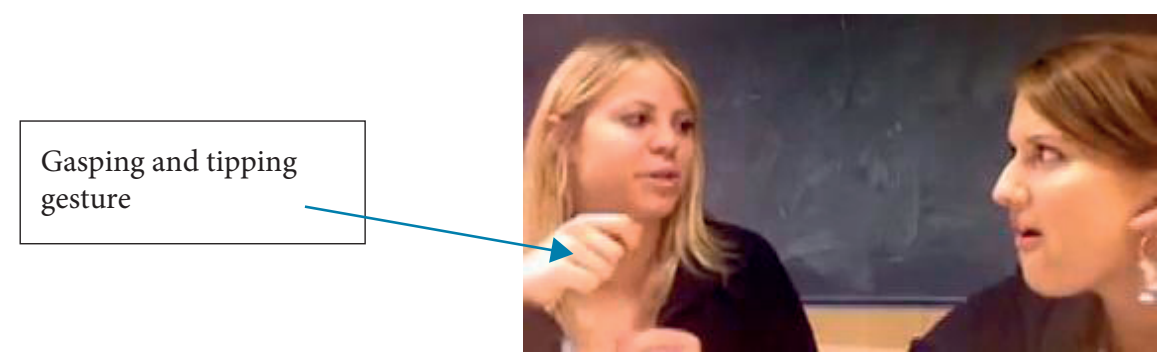

Janie's next turn (line 23) displays understanding of this elaboration with a change of state token (Heritage 1984) "oh" and acknowledging expression, with raised eyebrows (Mondada 2011) and opened mouth, but Amy continues modifying her verbal description further to "like liquid in a like little gel packet or something" (lines 25 and 27). Amy's gesture (below), which is the final gesture made in reference to the object, repeats the first she made in initiating repair as she says "little gel packet" (line 27).

This gesture mirrors her initial description and gesture in line 16 in a way that clarifies the nature of the object she is talking about, including the size (little, about two inches), shape (flat), characterization (packet rather than pouch), and even material (gel). By employing description and gesture, Amy and Janie 


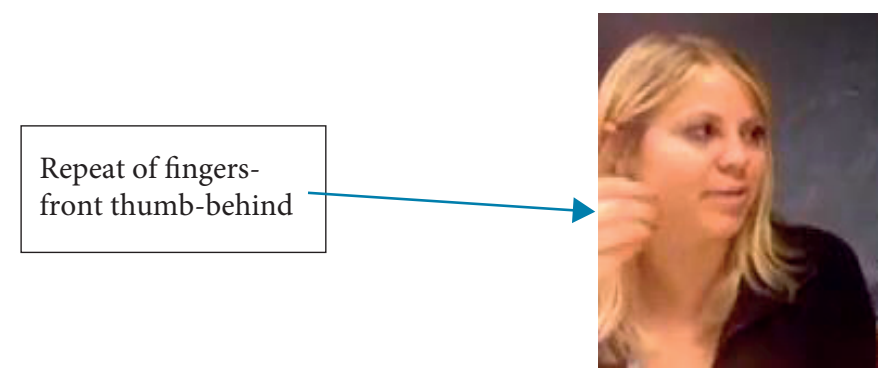

achieve an intersubjective match on the meaning of the pocket shot with relation to its attributes and, in identifying a use for it (lines 32-36), come to a new shared assessment and stance (Haddington 2006) toward pocket shots (as a "good idea" versus "terrible" and "disgusting").

Excerpts 1 and 2 illustrate techniques for repairing misunderstanding of the meaning of a single referent across the data, including repair on an unrecognized referent versus a misrecognized referent, and repair which quickly follows a trouble source versus a repair which occurs when trouble is realized outside the expected repair space. In the first example, the description is dependent on the meaning of the referent "Shortround," necessitating that this was understood in order for the participants to make shared sense of the talk. In the second example, the referent seems clear to both and there is a highly convergent assessment about it which is not necessarily changed by correcting the misapprehension. However, the story is expanded to produce new visual understandings of the pocket shot and eventual new (but still shared) stances, allowing the story to do more affiliative work. In this way the potential loss of intersubjectivity yields a more meaningful form of intersubjectivity: emphasizing shared stance and not just shared reference (Kärkkäinen 2007). The next section examines how similar-looking repairs - repairs that purport to fix references - are used to avoid addressing implicit inferences that could lead to intersubjectivity loss and trouble.

\subsection{Misunderstanding for managing trouble}

The previous section analyzed techniques through which participants accomplish misunderstandings with referential repairs on recognitions of referents or words. The next section analyzes how misunderstandings may use similar repair techniques to exploit inferential ambiguities and manage trouble. The first example shows how misrecognition is produced to avoid trouble over a problematic facial expression; the second example purports to be a misinterpretation/mishearing to avoid the implications of an inappropriate sexual joke; and the third example 
illustrates misunderstanding being used to avoid conflict and let someone off the hook for implicit disagreements over a prior action.

In Excerpt 3, Jill and her friend are visiting their friend Christa. Jill, who has a cold, has been coughing throughout the exchange. At the beginning of this excerpt, Jill has just coughed twice, then accuses Christa of having displayed a negative stance (Svennevig 2004) in response to Jill's coughing.

(3) "A Mean Look"

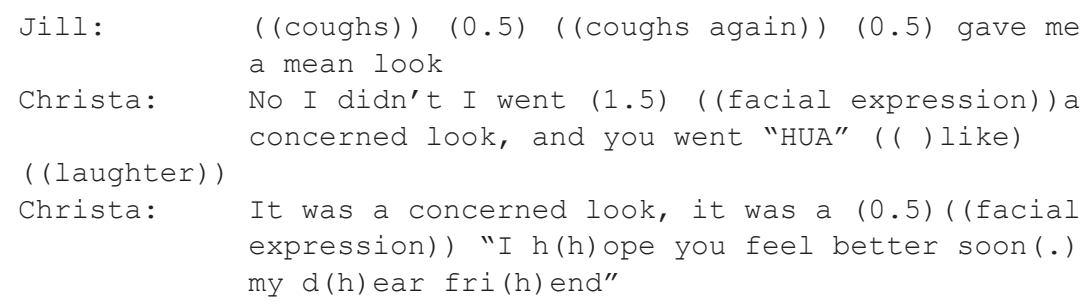

This example features a repair on a term purporting to gloss a facial expression and what emotion it allegedly conveyed - a repair on an action as 'showing reproach' versus 'showing concern.' In line 2, Jill characterizes Christa's facial expression, delivered toward her in response to Jill's coughing, as a "mean look." Christa immediately disaligns with this interpretation and "quotes" the face she made (Streeck 1988), re-interpreting it as a "concerned look" (line 4). In doing so, she treats Jill's candidate interpretation of her facial expression as disaffiliative (Antaki 2012) and as an opportunity for repair by actually repairing the face she originally made (though her expression bears a resemblance to the first). After making a joke about the intensity of Jill's cough, followed by laughter among all, Christa re-repairs and re-characterizes the facial expression. First recycling the gloss of "a concerned look" and re-producing the face (which again bears a resemblance to both the original and first repair in line 3), Christa then quotes a verbal formulation of the expression.

This quotation (lines 7-8) is not just a description of the "look," but is delivered as a sort of propositional equivalent, something she might have said in place of or alongside the look if she had spoken. The quote presents itself as what Christa would have 'had in mind' when delivering the look, once again asserting positive (concerned) intentions rather than negative (mean, annoyed) intentions. In doing so, Christa simultaneously enacts a repair on an asserted misinterpretation (by Jill) of her facial expression, and accomplishes a mild disagreement with Jill's characterization of Christa's internal emotional state. However, by treating the disagreement as arising from a misrecognition of the stance Christa's face allegedly displayed, an attention to the possible inferential mismatch is avoided. Trouble (and potentially opening a disagreement sequence) is avoided by not 
delving into whether Christa is actually annoyed at Jill's coughing, which could require (1) some indexical or background knowledge to ascertain as a reasonable interpretation on Jill's part (for example: that Christa is a known 'germophobe'); (2) knowledge of the prior discourse context (a recording earlier in the day in which Jill worries that Christa won't appreciate her coming over to Christa's house "sick"); and (3) a deeper examination into the tone in which Christa produces her account of concern (which comes across as possibly ironic - see for example Edwards 2000) in light of what the participants know of her character (that she does not typically display emotion seriously or straightforwardly).

As in the last case, this example demonstrates how trouble may be side-stepped by attending to potential inferential problems as remediable through recognition repairs. In this excerpt, six friends - all romantic couples - are eating dinner when one participant brings up an overheard utterance that occurred earlier in the evening.

(4) "Taking things out of context"

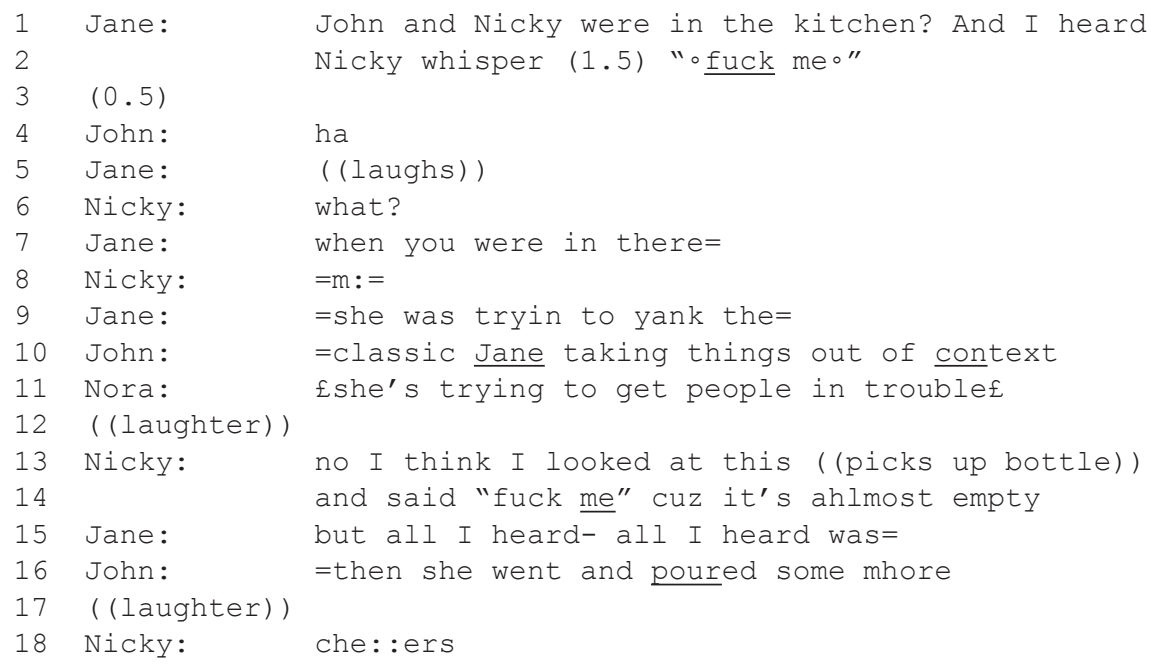

Nicky's "what" (line 6) is hearable as a trouble potentially with attention, hearing, or speaking in regard to Jane's turn (lines 1-2). However, subsequent turns indicate neither of these are the trouble source, indicating that the "what" may function rather as an open class repair (Drew 1997) signaling an inappropriate prior turn. Jane does treat Nicky's turn as a request for an account or explanation, which she partly directs to Nicky (line 7, "you") and partly directs to the others present (line 9, "she"). The others also see explanation as relevant: John reformulates the meaning of Jane's quotation as an example of Jane "taking things out of context" (line 10), and this could be proposed as accidental (Jane misheard, for instance) 
or intentional (Jane deliberately misheard). The latter interpretation is ratified by Nora in line 11.

Nicky then ends up providing her own reformulation of the event Jane describes. Her turn-initial "no" (line 13) could be directed toward the prior candidate explanations, or it could be directed toward Jane's initial characterization of the event. The latter interpretation is strengthened by Nicky's re-quoting of her alleged request-for-sex - culturally hearable in the contextualization cues of whispering and emphasis on the word "fuck," as it was initially produced by Jane in line 2 . The repair on Jane's formulation is accomplished by shifting the emphasis to the word "me" (line 14), which makes the phrase re-hearable as a response cry (Goffman 1978) of dismay. Nicky contextualizes the re-quotation by re-enacting a relevant object of the event: while saying "I think I looked at this" (line 13), her deictic reference to "this" is filled in when she simultaneously reaches for, grasps, and picks up briefly (before setting back down) a bottle of wine in the middle of the table. This indicates that her "dismay" was in response to the dwindling supply of wine, and this interpretation of events is ratified by the subsequent turn in line 16.

Nicky's responses to Jane constitute an interesting instance of other-initiated (next turn) and other-completed repair (third turn) repair, both dispreferred moves. Even after this, Jane continues to maintain her initial interpretation based on "all she heard" (line 15), indicating that she is accomplishing a different sort of action than straightforward reporting (as she was accused of doing - "trying to get people in trouble"), but her turn is cut off and the sequence closed in lines 17-18. Here, trouble is made relevant firstly with the production and the interpretation of the prior spoken utterance "fuck me" to which only three people - Nicky, John, and the overhearing Jane - originally had access. The trouble with this repairable is identifying what action it was doing (request or expression) on the basis of how it was said (with the emphasis on "fuck" or "me").

But a second lack of convergence, which is less obvious, is on the implications of this difference. If the "fuck me" was a request for sex, then it was directed toward the only other co-present person in the kitchen at the time, John - who is not Nicky's husband Jim (who is present but doesn't speak during the excerpt), but who is Nora's husband. Even if Jane's attempts to "get people in trouble" are a form of light-hearted teasing, Nicky appears to have a stake in denying what is actually an implicit, if non-serious, accusation of infidelity. Her repair on Jane's turn is therefore not just a correction of interpretation, but a disagreement with its implications - it's not really a 'misunderstanding.' By treating this disagreement as an easily-remedied result of a simple misunderstanding or misinterpretation, trouble is avoided and the conversation can move on.

The next example provides a case in which misrecognition is enrolled to 'draw out' a problematic inference, the disagreement-relevant pursuit of which is 
ultimately abandoned in favor of a more charitable reading as a misunderstanding. This excerpt comes from a series of home movies; one of the speaking participants $(J R)^{1}$ is behind the camera. JR has been filming her younger sister Sam, who is sitting on the floor of their shared bedroom flipping through a magazine (a younger brother is visible in the background but does not contribute).

(5) "The cherry ring"

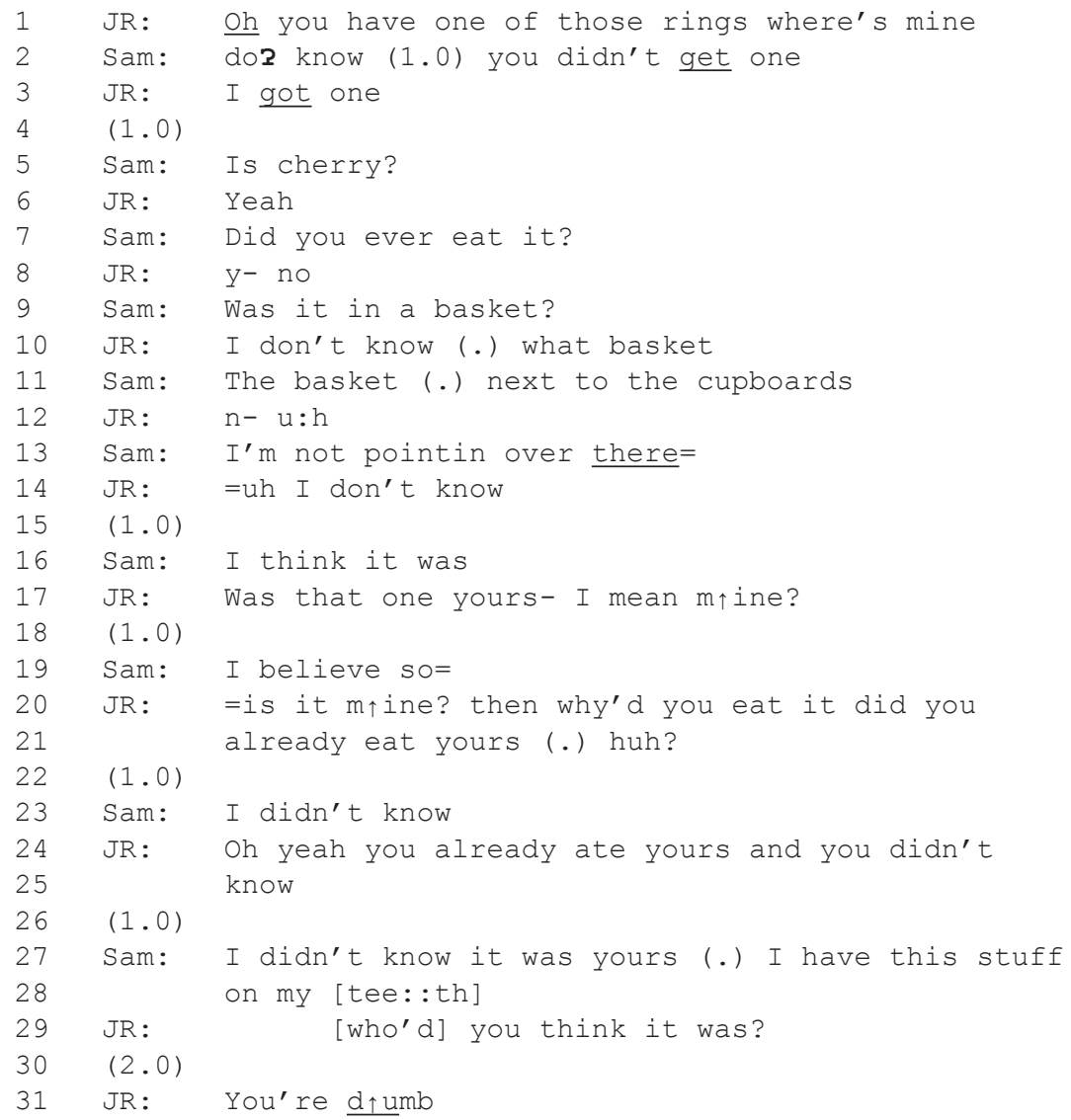

JR zooms in on the magazine just prior to line 1, which makes visible that Sam has a red "candy ring" on her finger (a kind of hard-crack confectionary in the shape of a stone affixed to a plastic ring meant to be worn on the finger and sucked). JR briefly brings the camera up to Sam's face, but then quickly moves it back down to the ring and makes the announcement on line 1 while zooming in on the ring now (below).

1. A younger version of the author. 


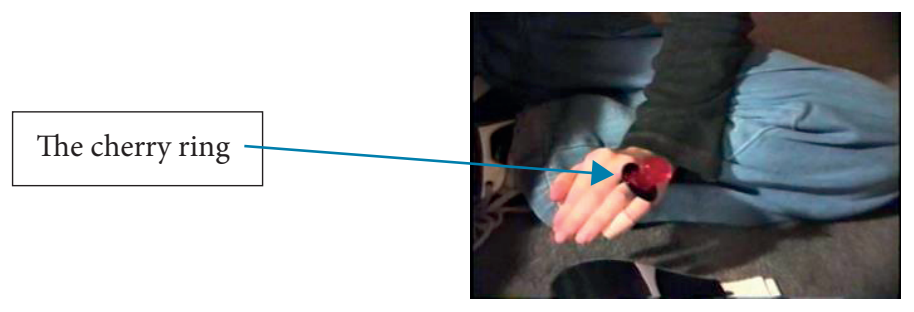

Following the announcement that Sam has "one of those rings" (which could mean a candy ring of a certain kind, or one of a set of candy rings available - it is not yet clear), JR asks “where's mine?" This makes relevant that "one of those rings" is, in fact, one of a collection available to both of them. Sam first claims ignorance, then suggests that there was no second ring available - more specifically, that JR did not "get" a ring (line 2). As she says this and the next several lines, Sam puts her hand, palm outward, to her mouth and intermittently chews/sucks on the ring between utterances while directing her gaze at the camera (below).

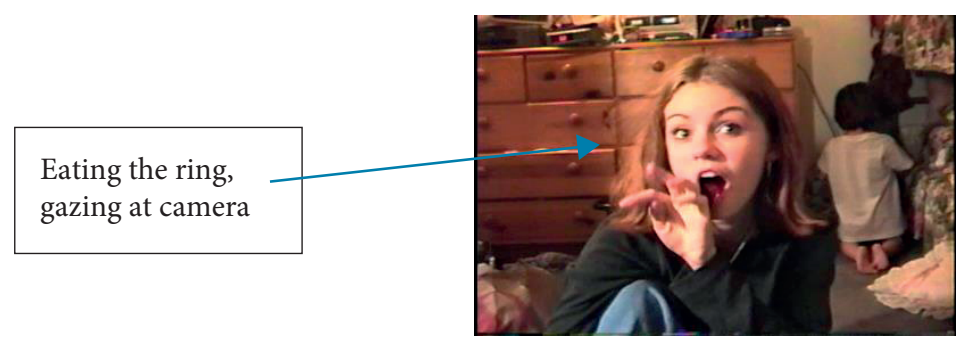

JR does not accept either of Sam's disavowals as adequate responses to her initial questions (line 3). After a pause Sam initiates a series of questions meant to discover what might have happened to JR's candy: whether the ring is "cherry" or cherry-flavored, if JR ever ate it, and whether the ring was in a basket (lines 5-9). These questions specify what sort of candy the ring was, whether it should still exist in the house somewhere, and where in the house the ring was likely to have been located. Sam displays more epistemic access (Heritage, 2012) to the ring than does JR, and this is confirmed by JR responding to the question of location with a repair requesting Sam specify to what basket Sam is referring. Sam gives a verbal formulation ("the basket next to the cupboards" line 11) to an assumedly shared sense of place while making a pointing gesture (her gaze continues to be directed to the camera). JR misinterprets this gesture, following it with the camera as though Sam were pointing to something in the room (below) and hovering around a jewelry basket while uttering the confused-sounding "uh" in line 12. Sam repairs JR's incorrect identification of the location of the basket (line 13), indicating that 
she means a different space with cupboards outside of the room they are in (but assumedly in the direction of another part of the house in which she was pointing).

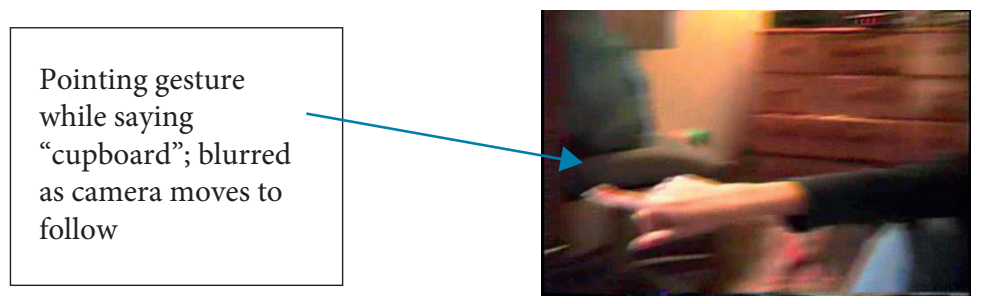

After establishing where the cupboards and the adjacent basket were not (though where they were hasn't been made explicit), Sam produces the turn "I think it was" while smiling, directing her gaze downward, and holding up her hand, ring side to the camera (line 16).

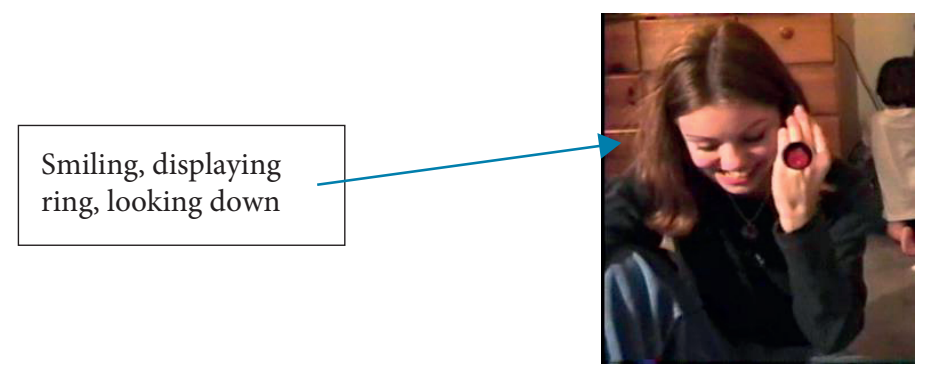

This turn is related not to the immediate prior turns, which are a repair on the reference to the basket, but to the base action of whether the cherry ring was in the basket. Her turn can be heard, therefore, as confirming that the cherry ring JR is referring to - the one she identified as "mine" in line 1 - was in the basket and is also the same one Sam is wearing on her hand. JR hears this implication and seeks confirmation (line 17). Since line 14, Sam's gaze has been directed downward, toward the magazine on the floor, and she continues to look down during the silence which may indicate an upcoming dispreferred response (Pomerantz 1984) at line 18. She then confirms with "I believe so" at line 19, framing this "belief" as something she has come to realize during the course of the current conversation (since admitting she knew all along would imply she deliberately violated the belief's attendant expectations: if there are two rings and she has already had one, then she should not eat the other because it belongs to JR). JR repeats her confirmation request in a higher tone at line 20, followed by a series of account demands delivered in quick succession that strongly imply Sam should have known the cherry ring belonged to JR. As this succession is accomplished, JR zooms in the camera, contributing to the presentation of her talk as an escalation of demands and pursuit of response. 

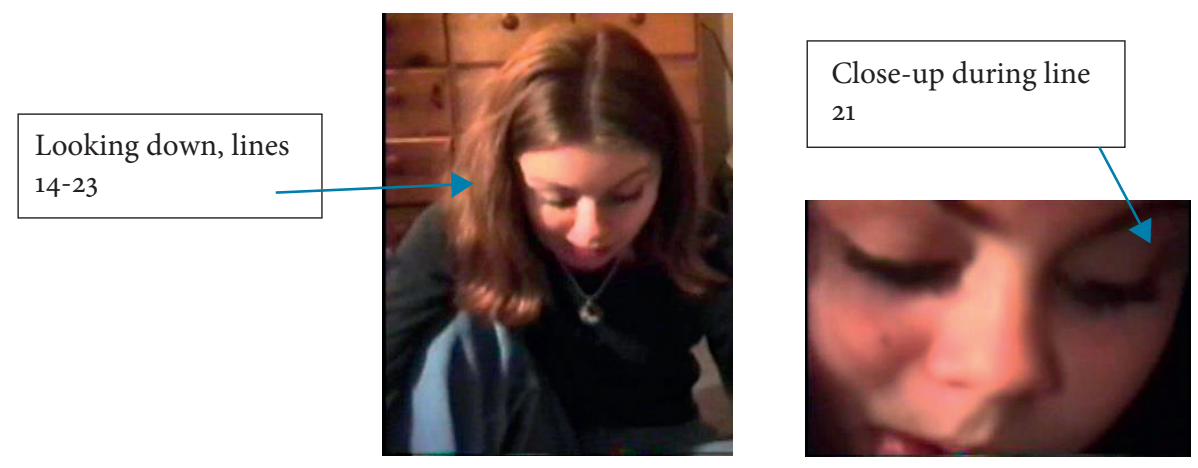

Although Sam does not explicitly admit having eaten 'hers,' she does not deny it either. Her next turn, "I didn't know," is delivered after another silence and seems to claim not to have known the other cherry ring was JR's, though it could also be claiming (albeit very implicitly) that Sam didn't know the rings were designated for each person. As she says "I didn't know," Sam does finally look up and into the camera again.

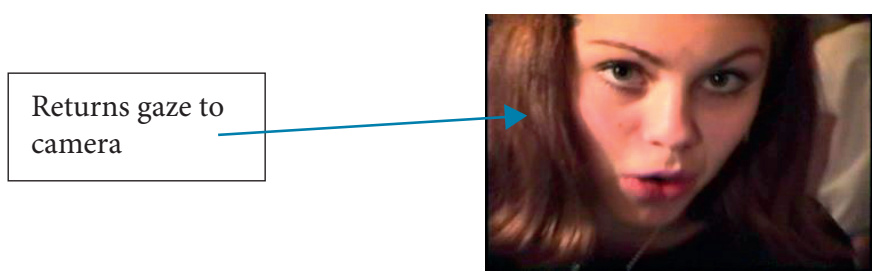

JR displays skepticism, formulating Sam's action of having eaten hers as well as her claim that she "didn't know" with a sarcastically-prefaced "oh yeah" (line 24). Sam looks down again and does not respond to JR's sarcasm with any form of account. Instead, after another pause, she delivers a complaint of having "this stuff on my teeth" (lines 27-28) while lifting her other hand (the one without the ring) to scrape her teeth (below). The "stuff" most likely refers to sticky residue that has accumulated as a result of chewing on the ring.

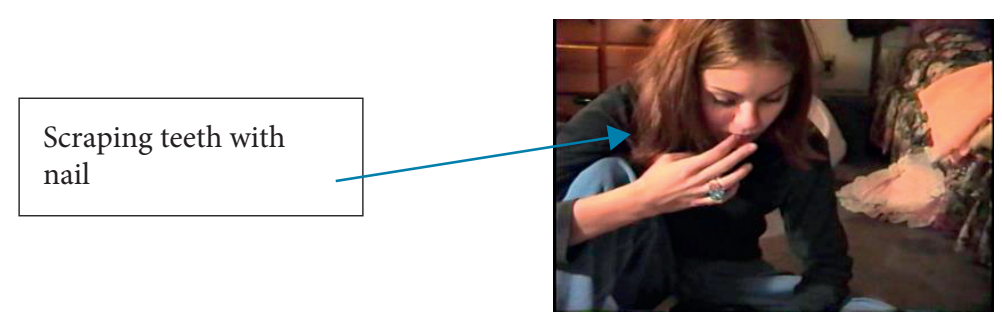


JR's next turn ignores this non-relevant turn and returns instead to the question of what Sam "knew." She treats Sam's turn at line 27 ("I didn't know") as a claim that Sam didn't know the ring was JR's, again using the evidence that Sam had already eaten her own ring (which Sam again doesn't deny) by asking whose ring Sam thought it (the one she is currently eating) was (line 29). Sam continues to look down and does not respond (below) and after another pause, JR announces that Sam is "dumb" (line 31).

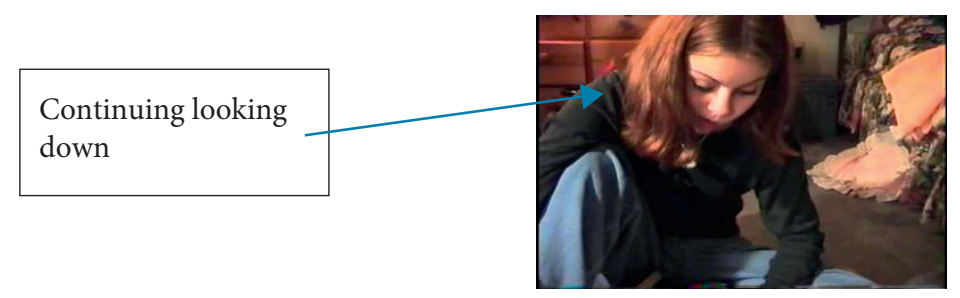

In this exchange, the sequence of turns slowly reveals that Sam is eating an item of candy that belongs to her sister. Over the course of the conversation, several points of understanding are negotiated in addition to and in service of uncovering this apparent 'fact': (1) there were two rings, making the rings a scarce commodity; (2) the ring Sam is eating is the second ring she has eaten, which would indicate that she already ate 'hers' and, therefore, is now eating 'JR's'; (3) the ring was in a basket that Sam appears to have known about but JR did not, and which contained at least the ring Sam is now eating; (4) JR appears to expect that one ring was designated for her and one for Sam, meaning anyone who has eaten two rings has eaten a ring that did not 'belong' to her. Relevant to these facts of recognizing and locating the ring in relation to other rings, as well as the expected division of rings, is the organization of knowledge with regard to these facts - a moral, accountable matter (Stivers, Mondada \& Steenstig 2011).

Sam seems to have more epistemic access to the rings; JR, though showing a skeptical stance toward Sam's apparent lack of knowledge about whose ring was whose, does not directly challenge Sam as lacking knowledge regarding the distribution of the rings. Despite the violation of what can be considered a moral norm an expectation of fairness, perhaps - it seems even more dispreferred to point out this interpretation than to offer every possible other interpretation. Perhaps Sam should have known that the rings would be shared - cuing relational and cultural expectations regarding the distribution of candy among siblings - but it would be worse to assume she did know that, but chose to ignore it. JR chooses to treat Sam as though Sam has made some misrecognition in need of repair. Sam never acknowledges this, and by saying little or aligning with the misunderstanding, she becomes complicit in producing the interaction as an uncovering of an error. 
JR could have intensified her pursuit by being more direct, or by upgrading her repair-like challenges, but either of these may have resulted in an acknowledgement that Sam ignored (rather than didn't know) the prescription with regard to sharing the rings. This conflict-relevant sequence would very likely have caused an argument.

In his 1992 paper, Schegloff demonstrated how third position repair features in the sorts of disalignments that can emerge from unrecovered intersubjectivity losses. In this example repair was not attempted solely on a referent, but on the divergent meanings of what people said and did with regard to one another, and the reasonableness of those actions. Using repairs on apparent misunderstandings was a way of avoiding problems: divergence was only partially pursued, with a 'lesser evil' proposed as the reason for the violation. Even the final insult "dumb" is delivered in a resigned tone, which lessens its impact, along with its substitution for a more serious violation, thereby emerging as a way of giving Sam the benefit of the doubt. The next section summarizes these results and their implications.

\section{The moral implications of "misunderstanding"}

In research in ethnomethodology and conversation analysis, intersubjectivity loss must be retrieved and righted, as it is the basis for intelligible interaction and, thus, for any course of social action. The usual righting mechanism is repair, which has its own operational constraints, for example being realized by the producer of the trouble-source as quickly as possible, and dealt with as quickly as possible (Schegloff, Jefferson \& Sacks 1977). Repairs on speaking and hearing lend themselves to this swift correction process. Recognition repairs on particular references - people, places, things, propositional meanings of turns, and so forth - can be more complex. However, though they may take several turns to right, recognition repairs seem to be the preferred form of repair on understanding. That is, given a trouble with understanding has occurred (rather than merely misspeaking or mishearing), the preference is to hear it as a misrecognition, preferably one which was accidental and cannot be strongly attributed to the speaker or hearer.

Sometimes, however, understanding troubles occur at another level, where possible reasons and intentions, multiplicities of interpretations, and potentially-divergent meanings of actions live. Intersubjectivity around assumptions and mutual inferential understanding (Sidnell 2014) requires an understanding, therefore, of sequences of turns, of their explicit content and actions as well as their implicit ones. And it is tightly interwoven with various indexical contexts in the world - identities, relationships, culture - which may be pragmatically relevant while not being articulated explicitly (Bilmes 1993). This analysis suggests that 
misunderstanding is a practice used to produce this sort of situated ideal: that it's not that we have different ideas of reality - or that we actually disagree about something - but that we have just made a mistake about how we use words, a mistake easily resolved through clarification (which is not to say simpler referential understandings never lead to trouble: c.f. Eckberg 2012; Schegloff 1992). So if a possible misunderstanding arises, hear it as a misrecognition; if it's hearable as an inferential mismatch, treat it as a misrecognition; and if you have to index disagreement over inferential differences, do it briefly and attribute it to a misrecognition.

It is also possible to use the concept of misunderstanding in order to do disagreement and conflict - for example, one can deliberately misunderstand, or pursue misunderstanding where there appears to be none, or pointedly violate the preference for treating potential trouble as misunderstanding by surfacing inferences. To illustrate this point, consider this simply-transcribed example, in which Kelsey has just asked Matt about his day, and he is narrating what he did in the first turn.

(6) "Sassy"

\begin{tabular}{|c|c|c|}
\hline 1 & Matt : & $\begin{array}{l}\text { Too long, an hour, two hours maybe. Went to work, } \\
\text { packed and }\end{array}$ \\
\hline 2 & & shipped some stuff, and then came to get you. \\
\hline & Kelsey: & Yeah you were kind of sassy. \\
\hline & Matt & $\begin{array}{l}\text { I was not sassy. Maybe I was- I was sassy because } \\
\text { you always call }\end{array}$ \\
\hline & & $\begin{array}{l}\text { right when I'm on my way, or right after I say that } \\
\text { I'm on my way, }\end{array}$ \\
\hline & & $\begin{array}{l}\text { you call and see where I am. Like, I'm driving, in } \\
\text { the snow. }\end{array}$ \\
\hline 7 & Kelsey: & $\begin{array}{l}\text { Fine we don't have to worry about it in the future } \\
\text { because I have }\end{array}$ \\
\hline & & my own car, hm? \\
\hline 9 & Matt : & $\begin{array}{l}\text { I know you do, but it's like I dunno do you think } \\
\text { it's courteous to }\end{array}$ \\
\hline & & $\begin{array}{l}\text { call somebody and check in on them every five } \\
\text { minutes? I mean, }\end{array}$ \\
\hline & & don't take it the wrong way. \\
\hline & Kelsey: & $\begin{array}{l}\text { You just took that to a whole other level. Screw } \\
\text { you, I don't want }\end{array}$ \\
\hline & & lk about this. \\
\hline
\end{tabular}

Garfinkel (1967) suggested that the morality of interaction is based in the expectations that our ordinary assumptions will be shared with others: that when we speak we will be understood, and that if we are not understood, things will be fixed as quickly and as minimally as necessary. Therefore, active topicalizations of divergent understandings may constitute an interference of order beyond any slight correctable error, becoming themselves accountable (Buttny 2012). The 
meanings of various elements in this conversation are unmatched. Sassiness is denied (line 4), then proposed as a reasonable response to a prior action (lines 4-6). The dismissal of the prior action as needing topicalization (lines 7-8) is rejected (lines 9-11), and a new candidate meaning for the action is proposed - not just unreasonableness, as initially stated (line 6), but a lack of courteousness (line 9). That Matt anticipates this suggestion will not be well received by Kelsey is imminent in his final disclaimer, "don't take it the wrong way" (line 11). That he was correct in his assumption is indicated by Kelsey's response in lines 12-13 which, in suggesting that the meaning of his prior turn was taking something to "a whole other level," demonstrates the extent to which Matt's pursuit of a misunderstanding is too great an interference, one that requires shutting down the sequence entirely. These are not troubles with recognitions of referential meanings, but troubles with inferential material on which the participants appear to disagree.

Future research could examine more ways in which misunderstandings are handled in interaction, or combine approaches (such as pragmatics and psychology; see Senft 2016). It would also be important to see how these interactions might play out differently in other contexts, such as institutional ones, or investigate what cultural variations might exist, or whether relationships make a difference. As a starting point, this analysis challenges the idea that any trouble may be attributable to misunderstanding, but also suggests some reasons why misunderstandings are invoked to explain trouble. Scholars have proposed that there has been a tendency in some research areas (such as intercultural communication) to treat disagreements as misunderstandings or miscommunication, much as we might in our own interactions, while ignoring how participants do otherwise (e.g., Bailey 2000; Cameron, 1998; Jacquemet 2005; Robles 2012). This is important because there are moral implications when conflict becomes relevant. Indeed, Garfinkel's (1967) breaches showed that it takes very little of such risky behavior to produce trouble.

\section{References}

Antaki, Charles 2012. "Affiliative and Disaffiliative Candidate Understandings." Discourse Studies 4: 531-547.

Bailey, Benjamin 2000. "Communicative Behavior and Conflict between African-American Customers and Korean Immigrant Retailers in Los Angeles." Discourse \& Society 11: 86-108.

Bilmes, Jack 1993. "Ethnomethodology, Culture, and Implicature: Toward an Empirical Pragmatics." Pragmatics 3: 387-409.

Bocéréan, C., and M. Musiol. 2009. "Mutual Understanding Mechanism in Verbal Exchanges between Carers and Multiply-disabled Young People: An Interaction Structure Analysis." Pragmatics 19: 161-177. 
Bolden, Galina B., Jenny Mandelbaum, and Sue Wilkinson. 2012. "Pursuing a Response by Repairing an Indexical Reference." Research on Language and Social Interaction 45: 137-155.

Bransford, John D., and Marcia K. Johnson. 1972. "Contextual Prerequisites for Understanding: Some Investigations of Comprehension and Recall." Journal of Verbal Learning and Verbal Behavior 11: 717-726.

Buttny, Richard 2012. Talking Problems: Studies of Discursive Construction. New York: SUNY Press.

Cameron, Deborah 1998. "Is There Any Ketchup, Vera?': Gender, Power and Pragmatics." Discourse \& Society 9: 437-455.

Cameron, Deborah 2001. Working with Spoken Discourse. Thousand Oaks, CA: Sage.

Craig, Robert T. 2008. “The Rhetoric of 'Dialogue' in Metadiscourse: Possibility-impossibility Arguments and Critical Events." In Dialogue and Rhetoric, ed. by Edda Weigand, 55-69. Amsterdam: John Benjamins.

Craig, Robert T., and Karen Tracy. 1995. "Grounded Practical Theory: The Case of Intellectual Discussion." Communication Theory 5: 248-272.

Dingemanse, M., S.G. Roberts, J. Baranova, J. Blythe, P. Drew, S. Floyd, R.S. Gisladottir, K.H. Kendrick, S.C. Levinson, E. Manrique, and G. Rossi. 2015. "Universal Principles in the Repair of Communication Problems.” PloS one 10: e0136100.

Drew, Paul 1997. “'Open' Class Repair Initiators in Response to Sequential Sources of Troubles in Conversation." Journal of Pragmatics 28: 69-101.

Drew, Paul 2012. "What Drives Sequences?” Research on Language \& Social Interaction 45: 61-68

Du Bois, John W. 2011. "Co-opting Intersubjectivity: Dialogic Rhetoric of the Self. In The Rhetorical Emergence of Culture, ed. by C. Meyer, and F. Girke, 53-83. Oxford, UK: Berghahn.

Duranti, Alessandro 2008. "Further Reflections on Reading Other Minds." Anthropological Quarterly 81: 483-494.

Finlay, Linda 2009. "Reflexive Embodied Empathy: A Phenomenology of Participant-researcher Intersubjectivity." The Humanist Psychologist 33: 271-292.

Ekberg, Stuart 2012. "Addressing a Source of Trouble Outside of the Repair Space." Journal of Pragmatics 44: 374-386.

Edwards, Derek 2000. "Extreme Case Formulations: Softeners, Investment, and Doing Nonliteral." Research on Language and Social Interaction 33: 347-373.

Edwards, Derek, and Jonathan Potter. 1992. Discursive Psychology. London: Sage.

Eriksson, Mats 2009. "Referring as Interaction: On the Interplay between Linguistic and Bodily Action." Journal of Pragmatics 41: 240-262.

Fox, Barbara 1999. Directions in Research: Language and the Body. Research on Language and Social Interaction 32: 51-60.

Garfinkel, Harold 1967. Studies in Ethnomethodology. Upper Saddle River, NJ: Prentice-Hall.

Gillespie, Alex, and Flora Cornish. 2010. "Intersubjectivity: Toward a Dialogical Analysis." Journal for the Theory of Social Behavior 40: 19-46.

Goffman, Erving 1978. “Response Cries.” Language 54: 787-815.

Goodwin, Charles 2000. "Action and Embodiment within Situated Human Action." Journal of Pragmatics 32: 1489-1522.

Goodwin, Marjorie. H. 1983. "Aggravated Correction and Disagreement in Children's Conversations.” Journal of Pragmatics 7: 657-677.

Haddington, Pentti 2006. "The Organization of Gaze and Assessments as Resources for Stance Taking.” Text \& Talk 26: 281-328. 
Hall, Barbara 2010. "Interaction is Insufficient: Why we Need Intersubjectivity in Course Room Discourse." Journal of eLearning and Online Teaching 1: 1-15.

Harwood, Irene N.H., Walter Stone, Walter, and Malcolm Pines. 2012. Self Experiences in Group, Revisited: Affective Attachments, Intersubjective Regulations, and Human Understanding. London, UK: Routledge.

Haselow, Alexander 2012. "Subjectivity, Intersubjectivity and the Negotiation of Common Ground in Spoken Discourse: Final Particles in English.” Language \& Communication 32: 182-204.

Hayashi, Makoto 2003. "Language and the Body as Resources for Collaborative Action: A Study of Word Searches in Japanese Conversation." Research on Language and Social Interaction 36: 109-141.

Hayashi, Makoto, Geoffrey Raymond, and Jack Sidnell. 2013. "Conversational Repair and Human Understanding: An Introduction.” In Conversational Repair and Human Understanding, ed. by M. Hayashi, G. Raymond, and J. Sidnell, 1-39. Cambridge: Cambridge University Press. Heath, Christian 2002. "Demonstrative Suffering: The Gestural (Re)embodiment of Symptoms." Journal of Communication 52: 597-616.

Hepburn, Alexa, Sue Wilkinson, and Rebecca Shaw. 2012. "Repairing Self- and Recipient Reference." Research on Language and Social Interaction 45: 175-190.

Heritage, John 1984. “A Change-of-state Token and Aspects of its Sequential Placement." In Structures of Social Action, ed. by J.M. Atkinson, and J. Heritage, 299-345. Cambridge: Cambridge University Press.

Heritage, John 1984. Garfinkel and Ethnomethodology. Cambridge, UK: Polity Press.

Heritage, John 1987. "Ethnomethodology." In Social Theory Today, ed. by Anthony Giddens, and Jonathan Turner, 224-272. Cambridge: Polity Press.

Heritage, John 2007. "Intersubjectivity and Progressivity in Person (and Place) Reference." In Person Reference in Interaction: Linguistic, Cultural and Social Perspectives, ed. by N. J. Enfield, and T. Stivers, 255-280. Cambridge, UK: Cambridge University Press.

Heritage, John 2012. “The epistemic Engine: Sequence Organization and Territories of Knowledge." Research on Language and Social Interaction 45: 30-52.

Hutchby, Ian, and Robin Wooffitt. 2008. Conversation Analysis. Cambridge, UK: Polity Press. Jacquemet, Marco 2005. “Transidiomatic Practices: Language and Power in the Age of Globalization." Language and Communication 25: 257-277.

Jefferson, Gail 1984. “Transcription Notation." In Structures of Social Action: Studies in Conversation Analysis, ed. by J.M. Atkinson, and J. Heritage, ix-xi. Cambridge, UK: Cambridge University Press.

Johansson, Eva 2007. "Empathy or Intersubjectivity? Understanding the Origins of Morality in Young Children." Studies in in Philosophy and Education 27: 33-47.

Johnson-Laird, P.N., and Ruth M.J. Byrne. 2002. "Conditionals: A Theory of Meaning, Pragmatics, and Inference." Psychological Review 109(4): 646-678.

Kärkkäinen, Elise 2007. "Stance Taking in Conversation: From Subjectivity to Intersubjectivity." Text \& Talk 26: 699-731.

Kataoka, K., and Y. Asahi. 2015. "Synchronic and Diachronic Variation in the Use of Spatial Frames of Reference: An Analysis of Japanese Route Instruction.” Journal of Sociolinguistics 19: 133-160.

Katriel, Tamar, and Gerry Philipsen. 1981. “'What we Need is Communication': 'Communication' as a Cultural Category in some American Speech.” Communication Monographs 48: 301-317. 
Kim, Kyu-Hyun 2001. "Confirming Intersubjectivity through Retroactive Elaboration: Organization of Phrasal Units in Other-initiated Repair Sequences in Korean Conversation." In Studies in Interactional Sociolinguistics, ed. by M. Selting, and E. Couper-Kuhlen, 345-372. Amsterdam: John Benjamins.

Koschmann, Timothy 2011. "Guest Editorial: Understanding Understanding in Action." Journal of Pragmatics 43: 435-437.

Kvale, Steinar 1983. “The Qualitative Research Interview: A Phenomenological and a Hermeneutical Mode of Understanding." Journal of Phenomenological Psychology 14: 171.

Lerner, Gene H., Galina B. Bolden, Alexa Hepburn, and Jenny Mandelbaum. 2012. "Preference Calibration Repairs: Adjusting the Precision of Formulations for the Task at Hand." Research on Language and Social Interaction 45: 191-212.

Levinson, Stephen 2006. “Cognition at the Heart of Human Interaction.” Discourse Studies 8: 85-93.

Lynch, Michael 2011. "Commentary: On Understanding Understanding." Journal of Pragmatics 43: 553-555.

Mikesell, Lisa 2014. "Conflicting Demonstrations of Understanding in the Interactions of Individuals with Frontotemporal Dementia: Considering Cognitive Resources and their Implications for Caring and Communication." In Dialogue and Dementia: Cognitive and Communicative Resources for Engagement, ed. By Robert W. Schrauf, and Nicole Müller, 147-180. Abingdon, UK: Psychology Press.

Mondada, Lorenza 2009. "Emergent Focused Interactions in Public Places: A Systematic Analysis of the Multimodal Achievement of a Common Interactional Space." Journal of Pragmatics 41: 1977-1997.

Mondada, Lorenza 2011. "Understanding as an Embodied, Situated and Sequential Achievement in Interaction." Journal of Pragmatics 43: 542-552.

Mundy, Peter, Connie Kasari, and Marian Sigman. 1992. "Nonverbal Communication, Affective Sharing, and Intersubjectivity." Infant Behavior and Development 15: 377-381.

Muntigl, P. , and K. T. Choi. 2010. "Not Remembering as a Practical Epistemic Resource in Couples Therapy." Discourse Studies 12: 331-356.

Osman, Gihan, and Susan C. Herring. 2007. "Interaction, Facilitation, and Deep Learning in Cross-cultural Chat: A Case Study." The Internet and Higher Education 10: 125-141.

Pomerantz, Anita 1984. "Agreeing and Disagreeing with Assessments: Some Features of Preferred/ dispreferred Turn Shapes." In Structures of Social Action, ed. by J. M. Atkinson, and John Heritage, 57-101. Cambridge: Cambridge University Press.

Robles, Jessida 2011. The Interactive Achievement of Morality in Everyday Talk: A Discourse. Analysis of Moral Practices and Problems in Interpersonal Relationships. Doctoral dissertation, University of Colorado at Boulder.

Robles, Jessica 2012. "Culture in Conversation." In Inter/cultural Communication: Representation and Construction of Culture in Everyday Interaction, ed. by Anastacia Kurylo, 89-114. Thousand Oak, CA: Sage.

Rochat, Phippe, Cláudia Passos-Ferreira, and Pedro Salem. 2009. "Three Levels of Intersubjectivity in Early Development." In Enacting intersubjectivity: Paving the Way for a Dialogue between Cognitive Science, Social Cognition and Neuroscience, ed. by Antonella Carassa, Francesca Morganti, and Guiseppe Riva, 173-190. Lugano, Switzerland: International Workshop.

Sacks, Harvey. 1992. Lectures on Conversation. Oxford: Basil Blackwell.

Sadler, Misumi 2010. "Subjective and Intersubjective Uses of Japanese Verbs of Cognition in Conversation." Pragmatics 20: 109-128. 
Schegloff, Emanuel A. 1987. "Some Sources of Misunderstanding in Talk-in-Interaction." Linguistics 25: 201-218.

Schegloff, Emanuel A. 1992. "Repair after Next Turn: The Last Structurally Provided Defense of Intersubjectivity in Conversation.” American Journal of Sociology 97: 1295-1345.

Schegloff, Emanuel A. 2007. Sequence Organization in Interaction Volume 1: A Primer in Conversation Analysis. Cambridge: Cambridge University Press.

Schegloff, Emanuel A., Gail Jefferson, and Harvey Sacks. 1977. "The Preference for Self-Correction in the Organization of Repair in Conversation." Language 53: 361-382.

Scobbie, James M., Sonja Schaeffler, and Ineke Mennen. 2011. "Audible Aspects of Speech Preparation." Proceedings of 17th ICPhS, Hong Kong, 1782-1785.

Senft, Gunter 2016. “"Masawa - bogeokwa si tuta!”: Cultural and Cognitive Implications of the Trobriand Islanders' Gradual Loss of Their Knowledge of How to Make a Masawa Canoe." Ethnic and Cultural Dimensions of Knowledge, 229-256. Springer International Publishing. Sidnell, Jack 2014. "The Architecture of Intersubjectivity Revisited." In Cambridge Handbook of Linguistic Anthropology, ed. by N. J. Enfield, P. Kockelman, and J. Sidnell, 364-399. Cambridge: Cambridge University Press.

Stivers, Tanya, Lorenza Mondada, and Jakob Steenstig. 2011. The Morality of Knowledge in Interaction. Cambridge, UK: Cambridge University Press.

Streeck, Jürgen 1988. "Grammars, Words, and Embodied Meanings: On the Uses and Evolution of so and like." Journal of Communication 52: 581-596.

Svennevig, Jan 2004. "Other-Repetition as Display of Hearing, Understanding and Emotional Stance." Discourse Studies 6: 489-516.

Svennevig, Jan 2008. “Trying the Easiest Solution First in Other-Initiation of Repair." Journal of Pragmatics 40: 333-348.

Wilkinson, Ray 1999. "Sequentiality as a Problem and Resource for Intersubjectivity in Aphasic Conversation: Analysis and Implications for Therapy." Aphasiology 13: 327-343.

Wootton, Anthony J. 1994. "Object Transfer, Intersubjectivity and Third Position Repair: Early Developmental Observations of One Child.” Journal of Child Language 21: 543-564. 


\section{Appendix}

\section{Jeffersonian transcription notations}

\begin{tabular}{|c|c|c|}
\hline Symbol & Name & Use \\
\hline Text [text] [text] & Brackets & $\begin{array}{l}\text { Start and end points of } \\
\text { overlapping speech. }\end{array}$ \\
\hline$=$ & Equal sign & $\begin{array}{l}\text { No hearable pause between } \\
\text { utterances. }\end{array}$ \\
\hline (\# of seconds) $(0.0)$ & Timed pause & $\begin{array}{l}\text { A number in parentheses } \\
\text { indicates the time, in seconds, of } \\
\text { a pause in speech. }\end{array}$ \\
\hline (.) & Micropause & $\begin{array}{l}\text { A brief pause, usually less than } \\
0.2 \text { seconds. }\end{array}$ \\
\hline . or $\downarrow$ & Period or down arrow & $\begin{array}{l}\text { Falling pitch utterance-final or } \\
\text { internal (respectively). }\end{array}$ \\
\hline ? or $\uparrow$ & Question mark or up arrow & $\begin{array}{l}\text { Rising pitch utterance-final or } \\
\text { internal (respectively). }\end{array}$ \\
\hline- & Hyphen & $\begin{array}{l}\text { An abrupt halt, cut-off or } \\
\text { interruption in utterance. }\end{array}$ \\
\hline$>$ text $<$ & Greater than / less than symbols & $\begin{array}{l}\text { Enclosed speech was delivered } \\
\text { more rapidly than usual for the } \\
\text { speaker. }\end{array}$ \\
\hline$<$ text $>$ & $\begin{array}{l}\text { Less than / greater than } \\
\text { symbols }\end{array}$ & $\begin{array}{l}\text { Enclosed speech was delivered } \\
\text { more slowly than usual for the } \\
\text { speaker. }\end{array}$ \\
\hline$\circ$ & Degree symbol & $\begin{array}{l}\text { Whisper or reduced volume } \\
\text { speech. }\end{array}$ \\
\hline TEXT & Capitalized text & $\begin{array}{l}\text { Shouted or increased volume } \\
\text { speech. }\end{array}$ \\
\hline$\underline{\text { text }}$ & Underlined text & $\begin{array}{l}\text { Emphasizing or stressing the } \\
\text { speech. }\end{array}$ \\
\hline$:::$ & Colon(s) & Prolongation of an utterance. \\
\hline (hhh) & $\mathrm{H}$ in parentheses & $\begin{array}{l}\text { Audible exhalation, laugh } \\
\text { particles, breathiness. }\end{array}$ \\
\hline (.hhh) &. $\mathrm{H}$ in parentheses & Audible inhalation. \\
\hline (text) & Parentheses & $\begin{array}{l}\text { Speech which is unclear or in } \\
\text { doubt in the transcript. }\end{array}$ \\
\hline$(($ italic text $))$ & Double parentheses & $\begin{array}{l}\text { Annotation of non-verbal activity } \\
\text { such as smiling, laughing, } \\
\text { pointing, etc. }\end{array}$ \\
\hline
\end{tabular}

(from Jefferson, 1984) 


\section{Additional notations}

\begin{tabular}{lll}
\hline Symbol & Name & Use \\
\hline$\#$ text\# & Hash/pound & Creaky, growly, gravelly, or guttural voice. \\
$\mathfrak{E t e x t £}$ & Italics & $\begin{array}{l}\text { High-pitched sing-song or smiley voice. } \\
\text { Speech which is unclear or in doubt }\end{array}$ \\
& $\mathrm{X}$ in parentheses & $\begin{array}{l}\text { and which could not be guessed or } \\
\text { approximated. }\end{array}$ \\
& IPA glottal stop & $\begin{array}{l}\text { Unvoiced consonant with slight nasal } \\
\text { quality. } \\
\text { Gesture, object, or expression of note in a }\end{array}$ \\
& Arrow & video screenshot. \\
\hline
\end{tabular}

\section{Author's address}

Jessica S. Robles

Loughborough University

Department of Social Sciences

Brockington Building, Loughborough

Leicestershire LE113TU

United Kingdom

j.j.robles@lboro.ac.uk 